\title{
Burnout among physicians and nursing staff working in the emergency hospital of Tanta University, Egypt
}

\author{
S.A.M. Abdo, ${ }^{7}$ R.M. El-Sallamy, ${ }^{1}$ A.A.M. El-Sherbiny ${ }^{7}$ and I.A. Kabbash ${ }^{1}$
}

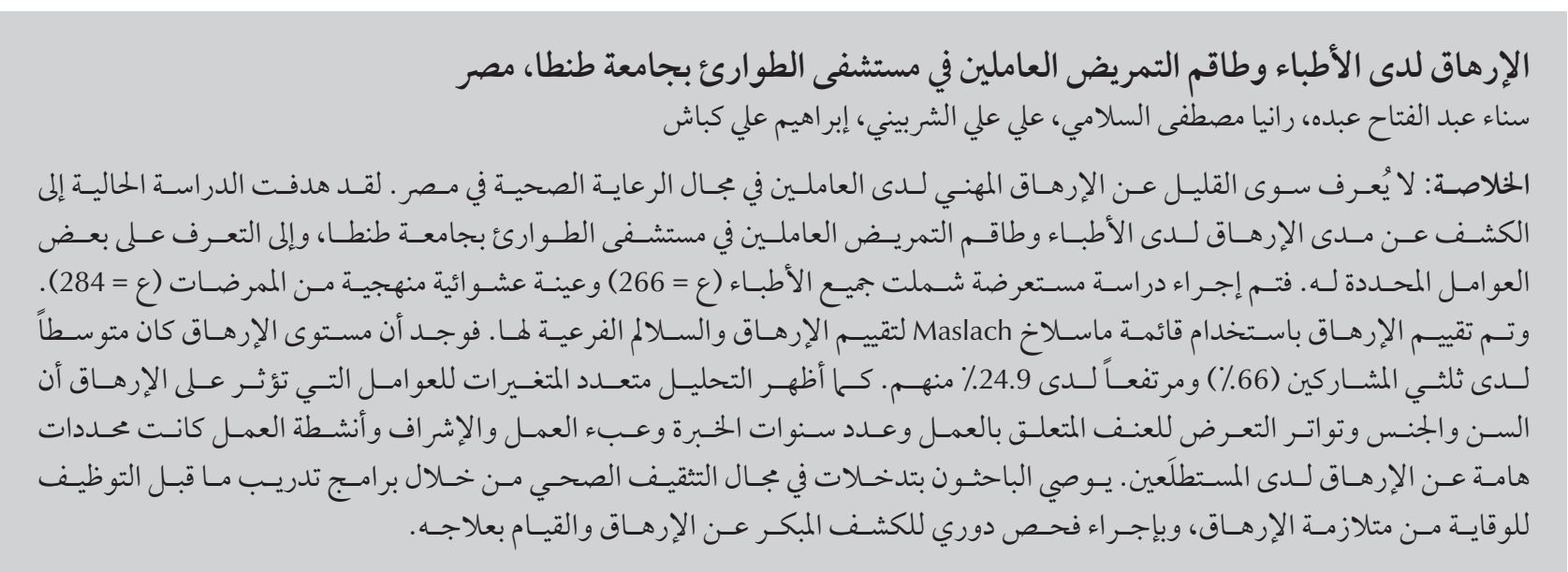

ABSTRACT Little is known about professional burnout among health-care workers in Egypt. The current study aimed to reveal the extent of burnout among physicians and nursing staff working in the emergency hospital of Tanta University and to identify some of its determinants. A cross-sectional study was carried out on all physicians ( $n=266)$ and a systematic random sample of nurses $(n=284)$. Burnout was assessed using the Maslach Burnout Inventory and its subscales. Most of the participants (66.0\%)had a moderate level of burnout and $24.9 \%$ of them had high burnout. Multivariate analysis of variables affecting burnout showed that age, sex, frequency of exposure to work-related violence, years of experience, work burden, supervision and work activities were significant predictors of burnout among the respondents. The authors recommend health education interventions during pre-employment training programmes for prevention of burnout syndrome and periodic screening for early detection and management of burnout.

L'épuisement professionnel chez des médecins et des personnels infirmiers au service des urgences de I'hôpital universitaire de Tanta (Égypte)

RÉSUMÉ Le syndrome d"épuisement professionnel chez les agents de santé en Égypte est assez mal connu. La présente étude visait à mettre en évidence la fréquence et l'étendue des cas d'épuisement professionnel chez des médecins et personnels infirmiers exerçant aux urgences de l'hôpital universitaire de Tanta et à identifier certains de ses déterminants. Une étude transversale a été menée auprès de tous les médecins $(n=266)$ et d'un échantillon aléatoire systématique des personnels infirmiers $(n=284)$. L'épuisement a été évalué à l'aide du Test d'inventaire de Burnout de Maslach et de ses sous-échelles. La plupart des participants (66,0\%) présentaient un niveau d'épuisement modéré tandis que pour 24,9\% d'entre eux il était élevé. Une analyse multivariée des variables ayant un impact sur l'épuisement professionnel a démontré que l'âge, le sexe, la fréquence des expositions à la violence liée au travail, les années d'expérience, la charge de travail, la supervision et les activités professionnelles étaient des facteurs prédictifs importants de l'épuisement professionnel chez les répondants. Les auteurs recommandent des interventions en matière d'éducation sanitaire au cours de programmes de formation avant l'entrée dans la vie active pour prévenir le syndrome d'épuisement professionnel, puis un dépistage systématique visant la détection précoce et la prise en charge de ce syndrome. 


\section{Introduction}

Burnout is considered an epidemic of modern society and the issue of occupational stress and burnout is receiving increasing attention worldwide. Burnout focuses on specific stressors in the workplace and the environmental pressures affecting the health of employed people (1). It was first described in the mid-1970s by Freudenberger and ever since it has been the subject of many studies (2). Burnout is a psychological term for the experience of long-term exhaustion and diminished interest. Despite this, burnout is not a recognized disorder in the Diagnostic and Statistical Manual of Mental Disorders (3).

Burnout syndrome can have a detrimental effect on employee satisfaction, work productivity, mental and physical health, rates of absenteeism and staff turnover and can affect family roles and functions (4). Burnout is an increasing problem among medical staff and is highly prevalent in health-care settings. It is associated with difficult working conditions and feelings of dissatisfaction with work (5). A study among German physicians found that more than one-third of the health-care professionals examined were experiencing professional burnout (6). Another study revealed that burnout can affect up to $45 \%$ of medical and nursing staff (7). The impact of burnout not only affects the suffering physicians but extends to their patients if the quality of medical care delivered is undermined (8).

Emergency services are the busiest and most stressful units of hospitals. Their staff might be at risk of burnout syndrome due to inadequate physical working conditions and emotional problems. Staff are under sustained stress owing to the crowded working environment, severity of cases treated and rotational work schedules that disrupt social and family relationships. Furthermore, conflicts with patients' companions, unsafe working environments, work difficulties and critical care decisions may play a role in the development of burnout syndrome (9).

Little is known about professional burnout among health-care workers in Egypt. The current study was conducted to reveal the prevalence of burnout among physicians and nursing staff working in the emergency hospital of Tanta University and to identify some of the determinants of burnout.

\section{Methods}

\section{Study design and setting}

A cross-sectional study was conducted over the period 1 November 2012 to 30 April 2013 in the emergency hospital of University of Tanta. This is a 450-bed hospital with the following departments: internal medicine, general surgery, neurosurgery, orthopaedics, burn care unit, toxicology, urology, radiology, intensive care unit and recovery unit. The hospital receives mainly injuries and road traffic accidents from Gharbia governorate and other nearby governorates, in addition to different surgical and medical emergency conditions. The hospital is staffed by 311 physicians who work in different departments in rotating shifts, 490 nurses, 78 head nurses and 70 ancillary workers and technicians. The study was approved by the internal review board of Tanta Faculty of Medicine.

\section{Sampling}

The inclusion criteria were physicians and nurses who were in post during the period of the study and consented to participate. The exclusion criteria were any physicians and nurses who had been employed at the hospital for less than 6 months and those who were on vacation during the study period.

The sample size was calculated using Epi-Info, version 2002. Based on a level of significance of $95 \%, 80 \%$ power of the study, estimated prevalence of burnout of 50\% and error of 5\%, the sample size was estimated to be 384 . The sample was increased to 523 to improve the validity of the results.

Out of the total of 311 physicians (146 resident physicians, 19 demonstrators and 146 assistant lecturers) 45 were excluded (42 had less than 6 months in the job and 3 were on vacation). Thus, 266 physicians were eligible to enter the study. Of these, 15 physicians refused to participate and 12 were unreachable. This represents a response rate of $89.8 \%$.

Of the 568 eligible nursing staff, 284 nurses from different departments were included in the study and selected by systematic sampling from the records of employed nurses, after removal of nurses ineligible for the study. The first nurse was chosen randomly from a computerized employment list and then the following every other nurse. The response rate of nurses was $100.0 \%$.

\section{Study tools}

The study participants were asked to fill a pre-designed self-administered questionnaire sheet that was designed for this study with sections on sociodemographic, work and health data; job satisfaction; and the assessment of burnout.

\section{Sociodemographic, work and health variables}

For the assessment of the determinants of burnout, data were collected about sociodemographic variables (age, sex, residence, marital status, number of family members, number of the rooms in the house, educational level); job characteristics and experiences (job type, department or ward type, years of experience, number of shifts per month, frequency of dealing with and caring for dying patients, previous exposure to work-related violence and its type, and private work outside the hospital); attitudes to work (absenteeism in the last 3 months; thoughts of changing job or moving to a different ward or department in the last 3 months); and health problems (diseases suffered; visits to a 
physician or admission to hospital in the last 3 months).

\section{Job satisfaction questionnaire}

The job satisfaction questionnaire included 7 main categories as follows:

- General working conditions (4 items about: hours worked each week, flexibility in scheduling, location of work and amount of paid vacation time/ sick leave offered).

- Pay and promotion potential (5 items about: salary, opportunities for promotion, benefits, e.g. health insurance, life insurance, job security and recognition for work accomplished).

- Work relationships (3 items about: relationships with co-workers, relationship(s) with supervisor(s) and relationships with subordinates, if applicable).

- Use of skills and abilities (3 items about: opportunity to utilize skills and talents, opportunity to learn new skills and support for additional training and education).

- Work activities (2 items about: variety of job responsibilities, degree of independence associated with work roles and adequate opportunity for periodic changes in duties).

- Work burden (4 items about: workload, time available for family, friends or leisure, work-related stress and administrative burden ).

- Supervision (3 items about: method of supervision, whether supervisor admits making errors or not and whether supervisor asks for advice before implementation of tasks).

Respondents were asked to rate how satisfied they were for each item on a 5-point Likert scale from 1 (extremely dissatisfied) to 5 (extremely satisfied). The satisfaction was arbitrarily classified as: dissatisfied (score $<33.3 \%$ ); average satisfaction (33.3-66.7\%); and satisfied (66.7-100.0\%).

\section{Maslach Burnout Inventory}

The Maslach Burnout Inventory (MBI), first reported by Maslach et al. in 1996, was the assessment instrument was used in the study (10). It has become the almost universally accepted gold standard to assess burnout (11) due to its high reliability and validity $(2,10)$. It was translated into Arabic and then back translated into English, to ensure correct translation of the questions. The Arabic version was revised by 7 experts and tested in a pilot study. The reliability of the questionnaire was tested by Cronbach alpha and found to be 0.81 .

The MBI includes 22 items with a 7-point Likert-type rating scale. Items are written in the form of statements about personal feelings or attitudes. The frequency scale is labelled at each point, ranging from 0 (never) to 6 (everyday). The maximum score of the total burnout scale is 132 . The MBI has 3 subscales: emotional exhaustion, which refers to both physical and mental exhaustion (statements no. 1-9); depersonalization, which consists of attitude changes of the individual when coming into contact with those who receive his/her services as he/she begins to display a cold and impersonal contact with suffering (statements no. 10-14); and reduced professional accomplishment, which measures perception of the influence of the others, well-being with his/her work, as well as the relationship with problems, evidencing a feeling of dissatisfaction (statements no. 15-22). Burnout is conceptualized as a continuous variable, ranging from a low to average to high probability of experiencing feelings of each element of burnout. A high degree of burnout is reflected in high scores on the emotional exhaustion (maximum score of 54) and depersonalization subscales (maximum score of 30) and in low scores on the reduced professional accomplishment subscale (maximum score of 48). An average degree of burnout is reflected in average scores on the 3 subscales. A low degree of burnout is reflected in low scores on the emotional exhaustion and depersonalization subscales and in higher scores on the reduced professional accomplishment subscale.

Subscales were classified into low, average and high level of burnout according to Table 1 (12). On the total burnout scale scores of 1-33 are considered as low, 34 - 66 as average and 67-99.9 as high level of burnout.

\section{Data collection}

A pilot test on $10 \%$ of the subjects (whose results were not included in the study) was carried out before starting data collection to determine potential obstacles, evaluate the adequacy of the designed questionnaire and to estimate the time needed to complete it.

Data were collected by asking the participants to fill the pre-designed self-administered questionnaire. Data collectors visited the hospital 5 days per week and collected an average of 5 questionnaire forms per day. The questionnaire was completed and returned to data collectors in the same session. Written and verbal consent were obtained from subjects prior to their

\begin{tabular}{lccc}
\hline Table 1 Classification of scores on subscales of the Maslach Burnout Inventory (MBI) (10) & & & \\
\hline MBI subscales & Lowel of burnout & High \\
& Average & $17-26$ & $>27$ \\
Emotional exhaustion score & $<16$ & $7-12$ & $>13$ \\
Depersonalization score & $>6$ & $38-32$ & $<31$ \\
Reduced professional accomplishment score & & $>39$ & \\
\hline
\end{tabular}


participation in the study and those who refused to participate were excluded. Confidentiality and privacy were guaranteed during the whole period of the study by anonymous completion of the questionnaires.

\section{Statistical analysis}

Organization, tabulation, presentation and analysis of data were performed using SPSS, version 19. Numerical data were presented as mean and standard deviation (SD). Student t-test, linear correlation and linear regression analysis were used for statistical analysis. Categorical data were presented as numbers and percentages and the chi-squared test was used for statistical analysis. When the chi-squared test was not appropriate, the Monte Carlo exact test was applied. The level of significance adopted was $P<0.05$.

\section{Results}

\section{Demographic data}

The questionnaires were completed by 523 staff: 284 nurses and 239 physicians. About one-third of staff had graduated from the secondary school of nursing $(31.2 \%)$, while $21.6 \%$ and $24.3 \%$ had graduated from the faculty of medicine with a bachelor of medicine or postgraduate degree respectively (Table 2).

The age range of participants was 20-53 years with a mean of 31.0 (SD 6.0) years. The majority of participants were aged below 40 years (91.8\%), female $(72.3 \%)$ and currently married (73.4\%) (Table 1). More than half were from urban areas (57.9\%). A total of $42.2 \%$ had a family size of $5+$. The majority of staff $(44.9 \%)$ had a crowding index at home of $1-1.5$.

\section{Work characteristics}

Table 3 shows that $31.0 \%$ of physicians dealt with critically ill patients a few times a year, $20.1 \%$ once a month and $21.3 \%$ once a week. In contrast, $22.5 \%$
Table 2 Sociodemographic characteristics of the studied health-care professionals $(n=523)$

$\begin{array}{lll}\text { Sociodemographic characteristic } & \begin{array}{c}\text { No. of } \\ \text { respondents }\end{array} & \%\end{array}$

\section{Age (years)}

20-

232

44.4

$30-$

248

$40-$

$50-$

Mean (SD)

Sex

Males $\quad 145$

Females

Residence

Urban

57.9

Rural

\section{Marital status}

Single

24.9

Married

73.4

Divorced

Widow

Family size (no.)

2

3

Mean (SD)

4.15 (1.30)

\section{Crowding index (no. of people/room)}

$\begin{array}{lr}<1 & 105 \\ 1- & 235 \\ 1.5- & 109 \\ 2- & 46 \\ 2.5+ & 28\end{array}$

\section{Educational level}

Secondary school (nurse) 163

High institute (nurse)

Graduate (nurse)

Graduate (physician)

Postgraduate (nurse or physician)

\section{Years of work experience}

$<10$

61.4

$10-$

28.5

$20+$

\section{Occupation}

Nurse

Head nurse

Resident

21.4

Demonstrator

Assistant lecturer

21.2

$S D=$ standard deviation . 


\begin{tabular}{|c|c|c|c|c|c|c|}
\hline \multirow[t]{2}{*}{ Variable } & \multicolumn{2}{|c|}{$\begin{array}{l}\text { Nurses } \\
(n=284)\end{array}$} & \multicolumn{2}{|c|}{$\begin{array}{l}\text { Physicians } \\
(n=239)\end{array}$} & \multirow[t]{2}{*}{$x^{2}$-value } & \multirow[t]{2}{*}{$P$-value } \\
\hline & No. & $\%$ & No. & $\%$ & & \\
\hline \multicolumn{7}{|c|}{ Frequency of dealing with critical patients } \\
\hline Never & 25 & 8.8 & 13 & 5.4 & & \\
\hline Few times a year & 46 & 16.2 & 74 & 31.0 & & \\
\hline Once monthly & 49 & 17.3 & 48 & 20.1 & 25.93 & 0.001 \\
\hline Once weekly & 64 & 22.5 & 51 & 21.3 & & \\
\hline Once daily & 23 & 8.1 & 20 & 8.4 & & \\
\hline More than once daily & 77 & 27.1 & 33 & 13.8 & & \\
\hline \multicolumn{7}{|c|}{ Exposure to work-related violence } \\
\hline Physical & 58 & 20.4 & 25 & 10.5 & 9.647 & 0.002 \\
\hline Verbal & 272 & 95.8 & 219 & 91.6 & 3.878 & 0.049 \\
\hline Sexual & 2 & 0.7 & 1 & 0.4 & & $1.000^{\mathrm{a}}$ \\
\hline
\end{tabular}

${ }^{a}$ Monte Carlo exact test.

of nurses dealt with critical patients once a week and $27.1 \%$ more than once daily. The difference between nurses and physicians was statistically significant $(P=0.001)$. The majority of physicians and nurses reported that they had been exposed to verbal violence at work (91.6\% and 95.8\% respectively $(P=0.049)$. Nurses were more exposed to physical violence than physicians $(20.4 \%$ and $10.5 \%$ respectively), a difference that was statistically significant $(P=0.002)$. Few respondents reported being exposed to sexual violence at work and the difference between nurses and physicians was not statistically significant $(P=1.000)$.

\section{Levels of burnout}

Table 4 shows that $46.9 \%$ of respondents scored high on emotional exhaustion, while $44.9 \%$ had average levels of depersonalization and a majority (97.7\%) had high levels of reduced personal accomplishment. Regarding the total burnout scale, most of the study subjects $(66.0 \%)$ were classified as

\begin{tabular}{|c|c|c|c|c|c|c|c|c|}
\hline \multirow[t]{3}{*}{ Subscale } & \multicolumn{6}{|c|}{ Level of burnout } & \multirow[t]{3}{*}{$x^{2}$-value } & \multirow[t]{3}{*}{$P$-value } \\
\hline & \multicolumn{2}{|c|}{ Low } & \multicolumn{2}{|c|}{ Average } & \multicolumn{2}{|c|}{ High } & & \\
\hline & No. & $\%$ & No. & $\%$ & No. & $\%$ & & \\
\hline Emotional exhaustion & & & & & & & 14.28 & 0.001 \\
\hline Nurses & 33 & 11.6 & 101 & 35.6 & 150 & 52.8 & & \\
\hline Physicians & 54 & 22.6 & 90 & 37.7 & 95 & 39.7 & & \\
\hline Total & 87 & 16.6 & 191 & 36.5 & 245 & 46.9 & & \\
\hline Depersonalization & & & & & & & 29.57 & 0.001 \\
\hline Nurses & 137 & 48.2 & 126 & 44.4 & 21 & 7.4 & & \\
\hline Physicians & 76 & 31.8 & 109 & 45.6 & 54 & 22.6 & & \\
\hline Total & 213 & 40.7 & 235 & 44.9 & 75 & 14.4 & & \\
\hline Reduced personal accomplishment & & & & & & & 4.171 & 0.041 \\
\hline Nurses & 0 & 0.0 & 10 & 3.5 & 274 & 96.5 & & \\
\hline Physicians & 0 & 0.0 & 2 & 0.8 & 237 & 99.2 & & \\
\hline Total & 0 & 0.0 & 12 & 2.3 & 511 & 97.7 & & \\
\hline Total burnout scale & & & & & & & 2.315 & 0.314 \\
\hline Nurses & 22 & 7.7 & 186 & 65.5 & 76 & 26.8 & & \\
\hline Physicians & 26 & 10.9 & 159 & 66.5 & 54 & 22.6 & & \\
\hline Total & 48 & 9.1 & 345 & 66.0 & 130 & 24.9 & & \\
\hline
\end{tabular}


having a moderate level of burnout and $24.9 \%$ as having high burnout.

More than half of nurses (52.8\%) experienced high emotional exhaustion compared with $39.7 \%$ of physicians, a difference that was statistically significant $(P<0.001)$. For the depersonalization subscale, $48.2 \%$ of nurses had low scores and $44.4 \%$ moderate scores, compared with $31.8 \%$ and $45.6 \%$ of physicians respectively, and the difference was statistically significant $(P<0.001)$. Almost all the physicians (99.2\%) experienced highly reduced feelings of personal accomplishment and the rate was slightly lower among nurses $(96.5 \%)(P=0.041)$. Regarding the total burnout scale, the difference between nurses and physicians was not statistically significant.

\section{Job satisfaction}

Table 5 shows that the majority of nurses and physicians had average levels of job satisfaction $(89.4 \%$ and $81.6 \%$ respectively), a difference that was statistically significant $(P=0.028)$. For general work conditions, $83.8 \%$ of nurses experienced average satisfaction compared with $61.9 \%$ of physicians $(P=0.001)$. Concerning promotion and financial aspects, $71.1 \%$ of nurses experienced average satisfaction compared with $74.9 \%$ of physicians $(P=0.001)$. For relationships in work, $64.8 \%$ of nurses were satisfied with their relationships with their colleagues, supervisors and subordinates compared with $60.3 \%$ of physicians $(P=0.019)$. Fewer nurses had an average satisfaction level regarding using skills and abilities (51.4\%) compared with physicians (69.9\%) $(P=0.020)$. Regarding work activities, the majority of nurses and physicians $(62.7 \%$ and $68.6 \%$ respectively) experienced average satisfaction and around one-fifth were dissatisfied $(21.8 \%$ and $21.8 \%$ respectively) $(P=0.020)$. The majority of nurses $(69.0 \%)$ and more than half of physicians (56.9\%) had average satisfaction regarding work burden. On the other hand, $28.5 \%$ and $38.5 \%$ of nurses and physicians respectively were dissatisfied with the work burden $(P=0.013)$. As regards supervision at work, $45.8 \%$ of nurses had average satisfaction compared with $56.9 \%$ of physicians $(P=0.001)$.

\section{Predictors of burnout}

Multivariate analysis by linear regression revealed that age, frequency of

\begin{tabular}{|c|c|c|c|c|c|c|c|c|}
\hline \multirow[t]{3}{*}{ Item } & \multicolumn{6}{|c|}{ Level of job satisfaction } & \multirow[t]{3}{*}{$\chi^{2}$-value } & \multirow[t]{3}{*}{$P$-value } \\
\hline & \multicolumn{2}{|c|}{ Dissatisfied } & \multicolumn{2}{|c|}{ Average } & \multicolumn{2}{|c|}{ Satisfied } & & \\
\hline & No. & $\%$ & No. & $\%$ & No. & $\%$ & & \\
\hline \multicolumn{9}{|c|}{ General work condition } \\
\hline Nurse & 17 & 6.0 & 238 & 83.8 & 29 & 10.2 & 38.21 & 0.001 \\
\hline Physician & 55 & 23.0 & 148 & 61.9 & 36 & 15.1 & & \\
\hline \multicolumn{9}{|c|}{ Promotion and financials } \\
\hline Nurse & 64 & 22.5 & 202 & 71.1 & 18 & 6.3 & 21.86 & 0.001 \\
\hline Physician & 24 & 10.0 & 179 & 74.9 & 36 & 15.1 & & \\
\hline \multicolumn{9}{|c|}{ Relationships in work } \\
\hline Nurse & 4 & 1.4 & 96 & 33.8 & 184 & 64.8 & 7.891 & 0.019 \\
\hline Physician & 14 & 5.9 & 81 & 33.9 & 144 & 60.3 & & \\
\hline \multicolumn{9}{|c|}{ Using skills and abilities } \\
\hline Nurse & 72 & 25.4 & 146 & 51.4 & 66 & 23.2 & 19.80 & 0.001 \\
\hline Physician & 44 & 18.4 & 167 & 69.9 & 28 & 11.7 & & \\
\hline \multicolumn{9}{|c|}{ Work activities } \\
\hline Nurse & 62 & 21.8 & 178 & 62.7 & 44 & 15.5 & 7.873 & 0.020 \\
\hline Physician & 57 & 23.8 & 164 & 68.6 & 18 & 7.5 & & \\
\hline \multicolumn{9}{|l|}{ Work burden } \\
\hline Nurse & 81 & 28.5 & 196 & 69.0 & 7 & 2.5 & 8.624 & 0.013 \\
\hline Physician & 92 & 38.5 & 136 & 56.9 & 11 & 4.6 & & \\
\hline \multicolumn{9}{|c|}{ Supervision at work } \\
\hline Nurse & 54 & 19.0 & 130 & 45.8 & 100 & 35.2 & 22.84 & 0.001 \\
\hline Physician & 63 & 26.4 & 136 & 56.9 & 40 & 16.7 & & \\
\hline \multicolumn{9}{|c|}{ Total job satisfaction } \\
\hline Nurse & 11 & 3.9 & 245 & 89.4 & 19 & 6.7 & 7.123 & 0.028 \\
\hline Physician & 20 & 8.4 & 195 & 81.6 & 24 & 10.0 & & \\
\hline
\end{tabular}


work-related exposure to violence, years of experience, work burden, supervision and work activities were the significant predictors for burnout (Table 6).

\section{Discussion}

Occupational-related burnout is increasingly recognized as a serious problem affecting many people working in the human services, particularly health-care workers, who suffer from negative feelings for self, work and life (13). Health-care professionals work with others in emotionally demanding situations and are exposed to their clients' psychological, socioeconomic and physical problems. As a result, burnout can easily develop, especially in sectors where critical care is provided (14). Burnout has been associated with absenteeism from work, ineffectiveness, interpersonal conflicts, lower productivity, job dissatisfaction, reduced organizational commitment and staff turnover. It predicts increased rates of illness, fatigue, substance misuse, depression, anxiety and irritability (15).

The aim of this study was to assess the prevalence of burnout syndrome among health-care workers of the emergency hospital, University of Tanta and to identify some of its determinants. About two-thirds of our study subjects had a moderate level of burnout and about one-quarter had a high level of burnout. This may be due to the overburdened health-care system in Egypt, especially the emergency sector, understaffing, especially among nursing staff, lack of resources, inadequate salaries, lack of control, difficult work schedules with long hours of work and frequent shifts, inadequate security and poor career advancement.

The results of studies on burnout are controversial, with some studies revealing alarmingly high rates of burnout among physicians, while other studies finding much lower rates. In

\begin{tabular}{lcc}
\hline Table 6 Multivariate analysis of variables affecting scores for total burnout on the \\
Maslach Burnout Inventory among the studied health-care professionals \\
\hline Variable & $\boldsymbol{t}$-value & $\boldsymbol{P}$-value \\
Age & 5.097 & 0.001 \\
Frequency of exposure to work-related violence & 4.567 & 0.001 \\
Years of experience & 3.969 & 0.001 \\
Work burden & 3.960 & 0.001 \\
Supervision & 2.669 & 0.008 \\
Work activities & 2.570 & 0.010 \\
\hline
\end{tabular}

Egypt, Yousef et al. in their study in Suez Canal University about the prevalence of burnout syndrome among residents of the university hospitals showed that $63.1 \%$ of the responding residents met the criteria for burnout (12). Elsewhere in the Eastern Mediterranean Region, Halayem-Dhouib et al. in Tunisia found that burnout syndrome was highly prevalent among nurses and medical residents (16). In Saudi Arabia, AlTurki et al. reported that the prevalence of burnout syndrome among multinational nurses was high (17). In contrast, a study carried out in Qatar found that $12.6 \%$ of the responding primary health-care physicians were experiencing burnout (18).

Previous European studies using the MBI reported widely varying burnout rates among medical and paramedical teams, ranging from $15-82 \%(19,20)$. The prevalence of burnout among staff of the departments of anaesthesia and critical care medicine was about $30 \%$ of nurses and $40-50 \%$ of physicians (21). Cydulka and Korte mentioned that previous estimates of burnout among emergency physicians in the United States of America range from 25-60\% and more than $90 \%$ among Canadian emergency physicians (22).

In African countries, high rates of burnout among maternal health staff at a referral hospital in Malawi have been reported (23). Other studies performed in Nigeria among health professionals (24) and in a Kenyan psychiatric hospital (25) have described high rates of burnout.
In South America, most studies on burnout syndrome were from Brazil. The prevalence of burnout syndrome among community-based health agents in the city of Sao Paulo was been estimated to be 24\% (26). Another Brazilian study performed on nurses in Santa Catarina showed that $35.7 \%$ displayed burnout (27).

In the last few years, several Asian studies have focused on burnout syndrome. From Singapore, Lim et al. reported that Singaporean nurses experienced high levels of stress related to work and emergency care (28). In Mongolia, a study by Bagaajav et al. detected an increasing level of stress among medical doctors. Excessive workload was a significant source of developing burnout, job stress and job dissatisfaction (29).

The Australian Medical Association performed a health survey on 914 Australian and New Zealand junior doctors and found that $69 \%$ had burnout symptoms (30).

The difference in the prevalence of burnout syndrome across different countries can possibly be explained by variations in culture, the nature of the health system (including structural and service delivery problems in different countries), patients' attitudes and the role of physicians as health-care providers. There are also differences in the assessment scales and study designs used in the various studies of burnout syndrome (31).

Almost half of our respondents (46.9\%) showed high emotional 
exhaustion, $97.7 \%$ showed highly reduced personal accomplishment and $14.4 \%$ showed high depersonalization. The subscale of reduced personal accomplishment reflects lower competence at work, which in turn affects the effectiveness of work leading to decreased quality of health-care services delivered.

Kalemoglu and Keskin in Istanbul, Turkey, reported that among emergencyservice personnel, $44.7 \%$ showed high emotional exhaustion, $33.2 \%$ high depersonalization and $28 \%$ high reduced professional accomplishment (9). A French study by Embriaco et al. found a high level of emotional exhaustion in 19\% of intensive care unit staff, high depersonalization in 37\% and highly reduced professional accomplishment in 39\% (7). A Belgian study of healthcare workers managing chronic patients with consciousness disorders reported that $33 \%$ showed moderate to severe emotional exhaustion, $36 \%$ showed moderate to severe depersonalization and only $3 \%$ presented low personal accomplishment (32).

Our study revealed that more than a half of nurses experienced high emotional exhaustion compared with physicians. Physicians had higher level of depersonalization than nurses and most of the physicians and nurses showed high reduced personal accomplishment. This is consistent with Gosseries et al., who reported that nurses were more emotionally exhausted than physicians. However, the rates of depersonalization and reduced personal accomplishment were greater in nurses even though the difference was not statistically significant (32). On the other hand, Escriba-Aguir et al., in their study on emergency medical and nursing staff in Spain, found that the prevalence of emotional exhaustion and reduced professional accomplishment was higher among doctors than nurses (33). Nursing staff are most likely to develop burnout due to the nature of their job, with many tasks, greater proximity and time spent with patients and relatives, and the emotional demands of their work (34).

Rajeev and Rashmi Khanna in Rajasthan in India found that 29.2\% of medical professional showed high levels of emotional exhaustion, $20.0 \%$ showed high depersonalization and $17.9 \%$ showed high reduced professional accomplishment (35). Among medical residents, Prins et al. found that rates of emotional exhaustion were $41-50 \%$ and depersonalization $34-70 \%$ (36), while in another study including nurses from different specialties, Sahraian et al. found reported rates of $23 \%$ for emotional exhaustion and 5\% for depersonalization. (34). In contrast, Abdulghafour et al. revealed that physicians in primary health-care centres in Kuwait had a relatively low mean percentage scores for emotional exhaustion and depersonalization, but they had high mean scores for personal accomplishment (8).

A great challenge encountered during emergency service is that the care of critical patients, such as undiagnosed cases, trauma patients with crush injuries and critical or dying patients, might lead to psychological depression in emergency service workers (9). Our study demonstrated a weak significant correlation between burnout and dealing with dying patients. Likewise, Poncet et al. (37) and Embriaco et al. (7) revealed that severe burnout was associated with end-of-life factors such as caring for dying patients.

Nurses in our study were more exposed to physical and verbal violence than were physicians. Kalemoglu and Keskin also demonstrated a high level of aggressive behaviour by patients and their companions in the emergency service. These aggressive acts might comprise personal threats or even use of weapons. This might complicate the safety of doctors, nurses and personnel taking care of patients and facilitate the development of burnout (9).
Multivariate analysis of variables affecting burnout in our study revealed that age, frequency of exposure to violence at work, years of experience, work burden, supervision and work activities were significant predictors of burnout syndrome among the study population. In Turkey, Demir et al. reported that problems with childcare were significantly associated with burnout among Turkish nurses (38). Lagerström et al. also reported work dissatisfaction, health threats and disequilibrium between family and work demands as the most important factors contributing to burnout among Iranian nurses (39).

A study on Cypriot physiotherapists in 2010 reported that regression analysis showed that the perception of stressful job, low salary, age group and employment sector predicted high burnout scores (14). Thomas and Valli in South Africa, reported that public hospital physicians had high levels of burnout syndrome and the main sources of stress were understaffing, lack of resources, difficult work schedules, inadequate job security and poor salaries. In addition, senior doctors showed lower job satisfaction (40).

The Australian Medical Association performed a health survey with 914 Australian and New Zealand junior doctors. Approximately $71 \%$ had low job satisfaction and 69\% had burnout symptoms and half of them reported that their workload was excessive (30). Meanwhile, Lee et al. found that physician burnout was negatively associated with autonomy and positive work attitudes. It was positively associated with workload, constraining organizational structure, incivility, conflicts, violence, low quality and safety standards, negative work attitudes, work-life conflict and contributors to poor mental health (41).

One of the limitations of our study is that a cross-sectional study is not considered the ideal tool to study the causes of burnout syndrome. 


\section{Conclusion and recommendations}

The present study in the emergency hospital of University of Tanta, Egypt concluded that about one-quarter of study nurses and physicians $(26.8 \%$ and $22.6 \%$ ) suffered from high levels of burnout syndrome. Age, frequency of exposure to violence at work, years of experience, work burden, supervision and work activities were significant predictors of burnout syndrome among the healthcare professionals studied. We recommend a longitudinal study to establish the causation of burnout syndrome; health education interventions during pre-employment training programmes for prevention of burnout syndrome; and periodic screening during work for early detection and management of burnout among health-care professionals.

\section{Finding: None.}

Competing interests: None declared.

\section{References}

1. Schaufeli WB, Greenglass ER. Introduction to special issue on burnout and health. Psychol Health. 2001 Sep;16(5):50110. PMID:22804495

2. Maslach C, Schaufeli WB, Leiter MP. Job burnout. Annu Rev Psychol. 2001;52:397-422. PMID:11148311

3. Kraft U. Burned out. Sci Am Mind. 2006; (June/July):28-33.

4. Tennant C. Work-related stress and depressive disorders. J Psychosom Res. 2001 Nov;51(5):697-704. PMID:11728512

5. De Oliveira GS Jr, Ahmad S, Stock MC, Harter RL, Almeida MD, Fitzgerald PC, et al. High incidence of burnout in academic chairpersons of anesthesiology: should we be taking better care of our leaders? Anesthesiology. 2011 Jan;114(1):181-93. PMID:21178674

6. Janus K, Amelung VE, Gaitanides M, Schwartz FW. German physicians "on strike"-shedding light on the roots of physician dissatisfaction. Health Policy. 2007 Aug;82(3):357-65. PMID:17137674

7. Embriaco N, Azoulay E, Barrau K, Kentish N, Pochard F, Loun$\operatorname{dou} \mathrm{A}$, et al. High level of burnout in intensivists: prevalence and associated factors. Am J Respir Crit Care Med. 2007 Apr 1;175(7):686-92. PMID:17234905

8. Abdulghafour YA, Bo-hamrab AM, Al-Randic MS, Kamel MI El-Shazly MK. Burnout syndrome among physicians working in primary health care centers in Kuwait. Alexandria Journal of Medicine. 2011;47:351-7.

9. Kalemoglu M, Keskin O. Burnout syndrome at the emergency service. Scand J Trauma Resusc Emerg Med. 2006;14:37-40.

10. Maslach C, Jackson SE, Leiter MP. Maslach Burnout Inventory manual. 3rd ed. Palo Alto (CA): Consulting Psychologist Press; 1996.

11. Schuttle N, Toppinen S, Kalimo R, Schaufeli W. The factorial validity of the Maslach Burnout Inventory across occupational groups and nations. J Occup Organ Psychol. 2000;73:53-66.

12. Yousef IM, Hosny AO, Elsayed OI, Ali EG. Burnout Syndrome among Resident Physician in Suez Canal University Hospital. Current Psychiatry Ain Shams University. 2006 March;13(1):24-43.

13. Sørgaard KW, Ryan P, Hill R, Dawson I; OSCAR Group. Sources of stress and burnout in acute psychiatric care: inpatient vs. community staff. Soc Psychiatry Psychiatr Epidemiol. 2007 Oct;42(10):794-802. PMID:17700977

14. Pavlakis A, Raftopoulos V, Theodorou M. Burnout syndrome in Cypriot physiotherapists: a national survey. BMC Health Serv Res. 2010;10:63. PMID:20222948

15. Knudsen HK, Ducharme LJ, Roman PM. Clinical supervision, emotional exhaustion, and turnover intention: a study of substance abuse treatment counselors in the Clinical Trials Network of the National Institute on Drug Abuse. J Subst Abuse Treat. 2008 Dec;35(4):387-95. PMID:18424048
16. Halayem-Dhouib S, Zaghdoudi L, Zremdini R, Maalej I, Béchir $M B$, Labbène R. Burnout en psychiatrie : une expérience tunisienne [Burnout among mental health professionals: a Tunisian experience]. Rev Epidemiol Sante Publique. 2010 Dec;58(6):403-8. PMID:21094003

17. Al-Turki HA, Al-Turki RA, Al-Dardas HA, Al-Gazal MR, AlMaghrabi GH, Al-Enizi NH, et al. Burnout syndrome among multinational nurses working in Saudi Arabia. Ann Afr Med. 2010 Oct-Dec;9(4):226-9. PMID:20935422

18. Abdulla L, Al-Qahtani DM, Al-Kuwari MG. Prevalence and determinants of burnout syndrome among primary healthcare physicians in Qatar. South African Family Practice Journal. 2011;53(4):380-3

19. Hyman SA, Michaels DR, Berry JM, Schildcrout JS, Mercaldo $\mathrm{ND}$, Weinger MB. Risk of burnout in perioperative clinicians: a survey study and literature review. Anesthesiology. 2011 Jan;114(1):194-204. PMID:21178675

20. Roth M, Morrone K, Moody K, Kim M, Wang D, Moadel A, et al. Career burnout among pediatric oncologists. Pediatr Blood Cancer. 2011 Dec 15;57(7):1168-73. PMID:21548010

21. Wallace JE, Lemaire JB, Ghali WA. Physician wellness: a misł sing quality indicator. Lancet. 2009 Nov 14;374(9702):1714-21. PMID:19914516

22. Cydulka RK, Korte R. Career satisfaction in emergency medicine: the ABEM Longitudinal Study of Emergency Physicians. Ann Emerg Med. 2008 Jun;51(6):714-722.e1. PMID:18395936

23. Thorsen VC, Tharp AL, Meguid T. High rates of burnout among maternal health staff at a referral hospital in Malawi: A crosssectional study. BMC Nurs. 2011;10:9. PMID:21605379

24. Onylezugbo E, Nawfor C. Construct validation of nurse's selfconcept questionnaire in Nigeria. Eur J Soil Sci. 2010;15:467-74.

25. Ndetei DM, Pizzo M, Maru H, Ongecha FA, Khasakhala LI, Mutiso $\mathrm{V}$, et al. Burnout in staff working at the Mathari psychiatric hospital. AfrJ Psychiatry (Johannesbg). 2008 Aug;11(3):199-203. PMID:19588043

26. Silva AT, Menezes PR. Burnout syndrome and common mental disorders among community-based health agents. Rev Saude Publica. 2008 Oct;42(5):921-9. PMID:18833390

27. Moreira DdeS, Magnago RF, Sakae TM, Magajewski FR. Prevalência da síndrome de burnout em trabalhadores de enfermagem de um hospital de grande porte da Região Sul do Brasil. [Prevalence of burnout syndrome in nursing staff in a large hospital in south of Brazil]. Cad Saude Publica. 2009 Jul;25(7):1559-68. PMID:19578577

28. Lim J, Bogossian F, Ahern K. Stress and coping in Singaporean nurses: a literature review. Nurs Health Sci. 2010 Jun;12(2):2518. PMID:20602699

29. Bagaajav A, Myagmarjav S, Nanjid K, Otgon S, Chae YM. Burnout and job stress among mongolian doctors and nurses. Ind Health. 2011;49(5):582-8. PMID:21804269 
30. Markwell AL, Wainer Z. The health and wellbeing of junior doctors: insights from a national survey. Med J Aust. 2009 Oct 19;191(8):441-4. PMID:19835538

31. Kolstad HA, Hansen AM, Kærgaard A, Thomsen JF, Kaerlev L, Mikkelsen S, et al. Job strain and the risk of depression: is reporting biased? Am J Epidemiol. 2011 Jan 1;173(1):94-102. PMID:21071605

32. Gosseries O, Demertzi A, Ledoux D, Bruno MA, Vanhaudenhuyse A, Thibaut A, et al. Burnout in healthcare workers mat naging chronic patients with disorders of consciousness. Brain Inj. 2012;26(12):1493-9. PMID:22725684

33. Escribà-Agüir V, Martín-Baena D, Pérez-Hoyos S. Psychosocial work environment and burnout among emergency medical and nursing staff. Int Arch Occup Environ Health. 2006 Nov;80(2):127-33. PMID:16710712

34. Sahraian A, Fazelzadeh A, Mehdizadeh AR, Toobaee SH Burnout in hospital nurses: a comparison of internal, surgery, psychiatry and burns wards. Int Nurs Rev. 2008 Mar;55(1):62-7. PMID:18275537

35. Khanna R, Khanna R. Is medicine turning into unhappy profession? Indian J Occup Environ Med. 2013 Jan;17(1):2-6. PMID:24082640
36. Prins JT, Gazendam-Donofrio SM, Tubben BJ, van der Heijden FM, van de Wiel HB, Hoekstra-Weebers JE. Burnout in medical residents: a review. Med Educ. 2007 Aug;41(8):788-800. PMID:17661887

37. Poncet MC, Toullic P, Papazian L, Kentish-Barnes N, Timsit $\mathrm{JF}$, Pochard F, et al. Burnout syndrome in critical care nursing staff. Am J Respir Crit Care Med. 2007 Apr 1;175(7):698-704. PMID:17110646

38. Demir A, UlusoyM, Ulusoy MF. Investigation of factors influencing burnout levels in the professional and private lives of nurses. Int J Nurs Stud. 2003 Nov;40(8):807-27. PMID:14568363

39. Lagerström $M$, Josephson $M$, Arsalani N, Fallahi-Khoshknab M. Striving for balance between family and work demands among Iranian nurses. Nurs Sci Q. 2010 Apr;23(2):166-72. PMID:20378918

40. Thomas LS, Valli A. Levels of occupational stress in doctors working in a South African public-sector hospital. S Afr Med J. 2006 Nov;96(11):1162-8. PMID:17167700

41. Lee RT, Seo B, Hladkyj S, Lovell BL, Schwartzmann L. Correlates of physician burnout across regions and specialties: a metaanalysis. Hum Resour Health. 2013;11(1):48. PMID:24074053 